Check for updates

Cite this: RSC Adv., 2018, 8, 8961

Received 11th January 2018

Accepted 19th February 2018

DOI: $10.1039 / \mathrm{c} 8 \mathrm{ra00326b}$

rsc.li/rsc-advances

\section{A base promoted one pot solvent free version of the Ramachary reductive coupling/alkylation reaction for the synthesis of 2,2-disubstituted ethyl cyanoacetates $\uparrow$}

\author{
Guangyou Jiang, $\$^{\mathrm{a}}$ Min Liu,,$^{\mathrm{a}}$ Dongmei Fang, ${ }^{\mathrm{b}}$ Ping Tan, ${ }^{\mathrm{a}}$ Min Huang, ${ }^{\mathrm{a}}$ Taiping Zhou, ${ }^{\mathrm{a}}$ \\ Zhenju Jiang, ${ }^{a}$ Zhihong $\mathrm{Xu}^{* a}$ and Zhouyu Wang (D) *a
}

An N,N-diisopropylethylamine promoted solvent-free Ramachary reductive coupling/alkylation (RRC/A) reaction for the synthesis of 2,2-disubstituted ethyl cyanoacetates has been developed. A series of 2,2disubstituted ethyl cyanoacetates were synthesized in one pot by the RRC/A reaction of commercially available aldehydes, ethyl cyanacetates, alkyl halides and Hantzsch ester. A solvent free two step multicomponent reaction has also been developed for the preparation of 2,2-dialkylated malononitriles and 2,2-dialkylated 4-nitrophenyl acetonitriles. All the designed RRC/A products could be easily obtained with good yields by these methods.
Cyanoalkyl moieties are found as important structural motifs in several nitrile-containing natural products and drugs. Nitrilecontaining compounds are also important synthons in organic synthesis because the cyano group can be easily converted into other functional groups (Fig. 1). Direct alkylation of simple alkylnitriles normally requires the utilization of strong

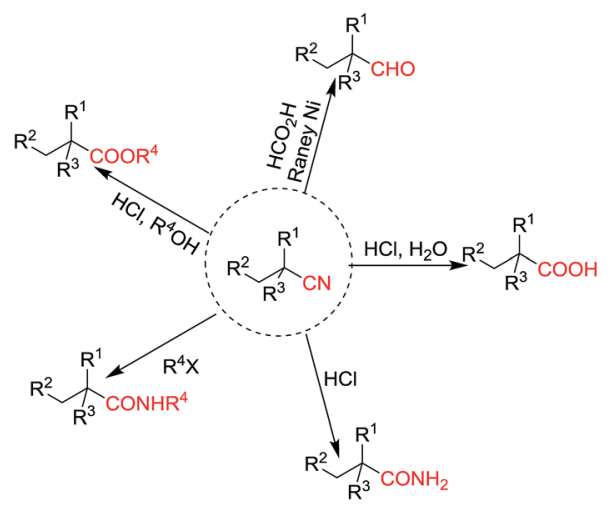

Fig. 1 Transformations of nitriles.

\footnotetext{
${ }^{a}$ Department of Chemistry, Xihua University, Chengdu, 610039, China. E-mail: zhouyuwang77@163.com; xzh1966@163.com; Fax: +86-028-8772-3006; Tel: +86028-8772-9463

${ }^{b}$ Chengdu Institute of Biology, Chinese Academy of Sciences, Chengdu, 610041, China $\dagger$ Electronic supplementary information (ESI) available. See DOI: $10.1039 / \mathrm{c} 8 \mathrm{ra00326b}$

\$ These authors contributed equally to this work and should be considered co-first authors.
}

bases, which are usually incompatible with base sensitive substrates. ${ }^{1-5}$ Thus, the activated nitriles such as $\alpha$-cyano esters, malononitriles were frequently used as substrate in the mild base catalyzed alkylation reactions. ${ }^{6}$ (Scheme 1).

During the last decade, there have been considerable advances in the organocatalysts catalyzed direct tandem reactions of activated nitriles. ${ }^{7-14}$ In 2006, Ramachary and coworkers reported the first L-proline catalyzed Knoevenagel/hydrogenation $(\mathrm{K} / \mathrm{H})$ and Knoevenagel/hydrogenation/alkylation $(\mathrm{K} / \mathrm{H} / \mathrm{A})$ for the preparation of substituted nitrile-containing products. ${ }^{13,14}$ The Ramachary reductive coupling (RRC) and Ramachary reductive coupling/alkalation (RRC/A) process could be done smoothly in $\mathrm{EtOH}$ at room temperature under the catalysis of L-proline to get the 2-alkylated cyano esters. In addition, lots of pharmaceutical intermediates and functionalized molecules were synthesized by the RRC and RRC/A reactions. ${ }^{15-24}$ Following this pioneering RRC reaction, we reported the first base-promoted RRC process in water for the preparation of a series of nitrile-containing products. ${ }^{25}$ The method provided convenient ways for the construction of nitrile-containing compounds in which the cyano group is attached to a tertiary carbon atom. For the construction of nitrile compounds in which the cyano group is attached to a quaternary carbon atom, Ramachary and coworkers used the RRC/A reaction. However, the alkylation reagents should be added after the completion of the RRC process. ${ }^{13,14}$ As part of our program to develop practical method for the construction of pharmaceutical products, ${ }^{25-29}$ here in, we report the first solvent free one-pot four components reaction for the preparation of 2,2dialkylated cyano esters from commercially available aldehydes, ethyl cyanacetates, alkyl halides and Hantzsch ester as shown in Scheme 1. 


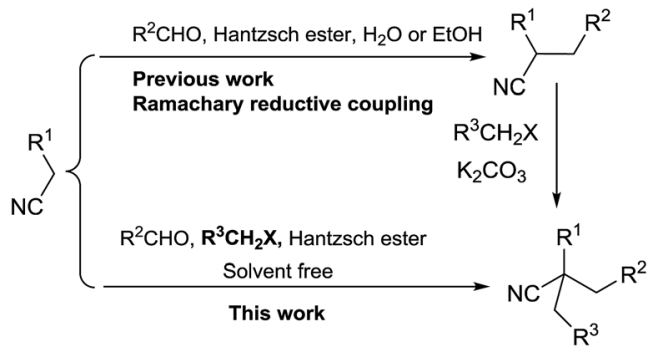

Scheme 1 Methods for the preparation of 2,2,2-trisubstituted nitriles.

At the onset of our study, malononitrile, 4-nitrophenyl acetonitrile, and ethyl cyanacetate were used, respectively, as model substrate in the reaction. When nitrile, 4-bromobenzaldehyde, benzyl bromide and Hantzsch ester were heated to $80{ }^{\circ} \mathrm{C}$, without the addition of base, no RRC/A product could be detected for all the tested nitriles in our study. When 2 equivalents of sodium bicarbonate were added in the reaction, the RRC/A product with $40 \%$ yield could isolated from the reaction in which the ethyl cyanacetate was used as starting material. For the reaction in which malononitrile and 4-nitrophenyl acetonitrile were used as starting material, respectively, the direct alkylation of these nitriles by the benzyl bromide were found as the major product under the otherwise identical reaction conditions. Thus ethyl cyanacetate was chosen as the model substrate in the further studies (Table 1).

Next we found the yield of the RRC/A product could be increased to $60 \%$ and $76 \%$, when 2 equivalents of sodium carbonate and potassium carbonate were added in the reaction, respectively. However, the yield of the RRC/A product was dropped to $5 \%$ when 2 equivalents of sodium hydroxide were added in the reaction. No more than $50 \%$ yield was obtained when organic base such as triethanolamine, 2-diethylamino ethanol and triethylenediamine were added in the reaction, respectively. Fortunately, we found $90 \%$ yield could be achieved when 2 equivalents of $N, N$-diisopropylethylamine (DIEA) were added under the otherwise identical reaction conditions. Decreasing the amount of DIEA to 1 equivalent, the yield of the $\mathrm{RRC} / \mathrm{A}$ product was dropped to $50 \%$. However, increasing the amount of DIEA to 3 and 4 equivalents, respectively, a low yield was also observed. Only trace amount of the RRC/A product was detected when the reactions were set up at $60{ }^{\circ} \mathrm{C}$ and $70{ }^{\circ} \mathrm{C}$, respectively. Increasing the reaction temperature to $90{ }^{\circ} \mathrm{C}$, the yield of the RRC/A product could be increased to $92 \%$. When the reaction was heated at $90{ }^{\circ} \mathrm{C}$ for 2 hours, $92 \%$ yield of the RRC/A product was observed. However, only $67 \%$ and $75 \%$ yields were obtained when the reaction time was cut down to 0.5 and 1 hour, respectively. After careful investigation, we identified the best reaction conditions in which the ethyl cyanacetate, 4-bromobenzaldehyde, benzyl bromide and Hantzsch ester were heated at $90{ }^{\circ} \mathrm{C}$ for $2 \mathrm{~h}$, and the RRC/A product could be obtained with $92 \%$ isolated yield.

With the optimized reaction conditions in hand, the substrate scope and limitations of the solvent-free one-pot four components reaction was studied (Fig. 2). We found, beside 4bromobenzaldehyde, other halide substituted benzaldehydes
Table 1 Base promoted Ramachary reductive coupling/alkylation reaction $^{a}$

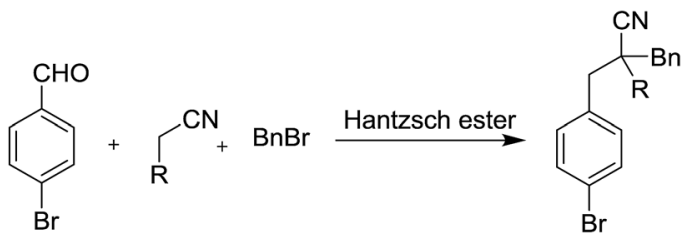

\begin{tabular}{|c|c|c|c|c|}
\hline Entry & $\mathrm{R}$ & Additives (eq.) & $\begin{array}{l}T \\
\left({ }^{\circ} \mathrm{C}\right)\end{array}$ & $\begin{array}{l}\text { Yield }^{b} \\
(\%)\end{array}$ \\
\hline 1 & $\mathrm{CN}$ & - & 80 & - \\
\hline 2 & $\mathrm{CN}$ & $\mathrm{NaHCO}_{3}(2.0)$ & 80 & - \\
\hline 3 & $4-\mathrm{NO}_{2} \mathrm{C}_{6} \mathrm{H}_{4}$ & 一 & 80 & - \\
\hline 4 & $4-\mathrm{NO}_{2} \mathrm{C}_{6} \mathrm{H}_{4}$ & $\mathrm{NaHCO}_{3}(2.0)$ & 80 & - \\
\hline 5 & COOEt & 一 & 80 & - \\
\hline 6 & & $\mathrm{NaHCO}_{3}(2.0)$ & 80 & 40 \\
\hline 7 & & $\mathrm{Na}_{2} \mathrm{CO}_{3}(2.0)$ & 80 & 60 \\
\hline 8 & & $\mathrm{~K}_{2} \mathrm{CO}_{3}(2.0)$ & 80 & 76 \\
\hline 9 & & $\mathrm{NaOH}(2.0)$ & 80 & 5 \\
\hline 10 & & TEOA (2.0) & 80 & 30 \\
\hline 11 & & DEAE (2.0) & 80 & 40 \\
\hline 12 & & DABCO (2.0) & 80 & 20 \\
\hline 13 & & DIEA (2.0) & 80 & 90 \\
\hline 14 & & DIEA (1.0) & 80 & 50 \\
\hline 15 & & DIEA (3.0) & 80 & 88 \\
\hline 16 & & DIEA (4.0) & 80 & 43 \\
\hline 17 & & DIEA (2.0) & 60 & - \\
\hline 18 & & DIEA (2.0) & 70 & - \\
\hline 19 & & DIEA (2.0) & 90 & 92 \\
\hline $20^{c}$ & & DIEA (2.0) & 90 & 67 \\
\hline $21^{d}$ & & DIEA (2.0) & 90 & 73 \\
\hline $22^{e}$ & & DIEA (2.0) & 90 & 92 \\
\hline
\end{tabular}

${ }^{a} 0.25 \mathrm{mmol}$ of 4-bromobenzaldehyde, $0.75 \mathrm{mmol}$ of $\mathrm{BnBr}, 0.30 \mathrm{mmol}$ of Hantzsh ester and $0.30 \mathrm{mmol}$ of nitrile were added in reaction tube, and heating for $12 \mathrm{~h} .{ }^{b}$ Isolated yield. ${ }^{c}$ Reaction time $0.5 \mathrm{~h} .{ }^{d}$ Reaction time $1 \mathrm{~h}$. ${ }^{e}$ Reaction time $2 \mathrm{~h}$. TEOA $=$ triethanolamine; DEAE $=2$ diethylamino ethanol; DABCO $=$ triethylenediamine. DIEA $=\mathrm{N}, \mathrm{N}$ diisopropylethylamine.

such as 4-cholorobenzaldehyde and 4-flurobenzaldehyde could also be used as good substrate in the reaction, and the RRC/A products 1b and 1c could be obtained with 95\% and 96\% yield when they were used in the reaction, respectively. The product 1d could be obtained with $94 \%$ yield when 4-methyl benzaldehyde was used in the reaction. The yield of RRC/A product 1e was dropped to $73 \%$ when 4-methoxyl benzaldehyde was used. And the yield of 1 f was further dropped to $24 \%$ when 4-cyano benzaldehyde was used in the reaction. However, when the 4-nitro benzaldehyde was used in the current reaction, the RRC/A product $1 \mathrm{~g}$ could be obtained with $76 \%$ yield. 1Naphthaldehyde could also be used in the reaction and the RRC/A product $1 \mathrm{~h}$ was obtained with $92 \%$ yield. Other aldehydes such as furan-2-carbaldehyde and thiophene-2carbaldehyde could also be used in the reaction, and the RRC/ A product $1 \mathbf{i}$ and $1 \mathbf{j}$ was isolated with $94 \%$ and $88 \%$ yields, respectively. No reduction RRC/A product could be obtained when acetophenone was used in the reaction. And aliphatic aldehydes such as propionaldehyde was not good substrate, 
<smiles>CCOC(=O)C(C)(Br)Cc1ccc(Br)cc1</smiles><smiles>CCOC(=O)C(Br)(Br)Cc1ccc(Cl)cc1</smiles><smiles>CCOC(=O)C([NH3+])(Br)Cc1ccc(F)cc1</smiles><smiles>CCOC(=O)C(C#N)(Cc1ccc([N+](=O)[O-])cc1)C(=O)OCC</smiles><smiles>CCOC(=O)C(Br)(Br)Cc1ccc(OC)cc1</smiles><smiles>CCOC(=O)C(C#N)(Cc1ccc(C#N)cc1)C(=O)OCC</smiles><smiles>CCOC(=O)C(Br)(C#N)Cc1cccc2ccccc12</smiles><smiles>[X]c1ccccc1CC(C)(C(=O)O)C(=O)OCC</smiles>

$1 \mathrm{i}, \mathrm{X}=\mathrm{S}, 94 \%$

$1 \mathrm{j}, X=0,88 \% \quad 1 \mathrm{k}$, none

1I, trace

Fig. 2 Substrate scope of the solvent-free one-pot four components reaction.

either. The low boiling point of propionaldehyde and lower reactivity of ketone may be responsible for it.

For the preparation of 2,2-dialkylated malononitriles and 2,2dialkylated 4-nitrophenyl acetonitriles, a base promoted one-pot two step RRC/A process was also developed. However, a selfcatalyzed RRC process was observed in the reaction of malononitrile, aldehyde and Hantzsch ester. The RRC product 2-(4-bromobenzyl) malononitrile could be obtained with $95 \%$ yield under the optimized reaction conditions. After the completion of the self-catalyzed RRC process, without any work up process, the benzyl bromide with DIEA were added, and then the RRC/A product 2 was obtained with $93 \%$ isolated yield. In the preparation of $\mathrm{RRC} / \mathrm{A}$ product 3 , both the RRC process and alkylation step need one equivalent of $N, N$-diisopropylethylamine. A series of derivatives of the nitrile compounds could be prepared by these two methods (for more details see ESI $\dagger$ ) (Scheme 2).

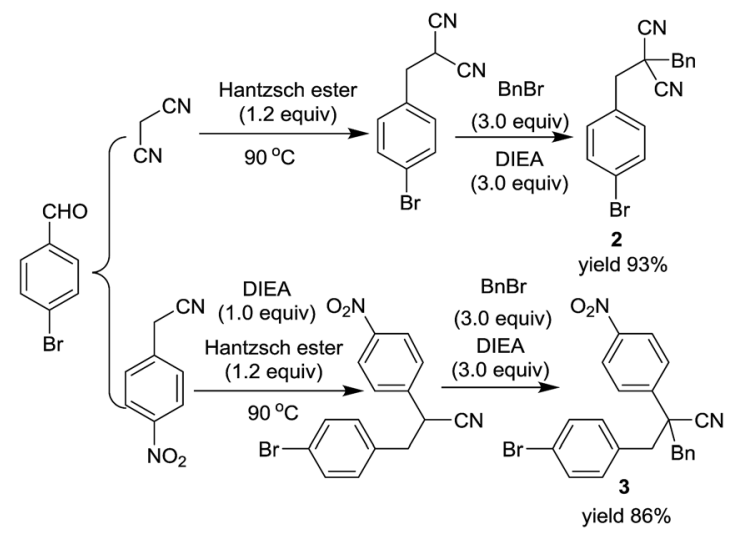

Scheme 2 Solvent-free one-pot two step RRC/A reaction.

In conclusion, an efficient one pot solvent-free four components RRC/A process for the synthesis of 2,2-dialkylated cyano esters has been described by the reaction of commercially available aldehydes, ethyl cyanacetates, alkyl halides and Hantzsch ester. The designed RRC/A products could be obtained with moderate to high yields. And a solvent free one pot two step RRC/A process has also been developed for the preparation of 2,2-dialkylated malononitriles and 2,2-dialkylated 4nitrophenyl acetonitriles. A series of malononitrile and 4nitrophenyl acetonitrile derivatives could be prepared by these two step RRC/A methods. Compared with the first RRC/A method, the diversity of the substrate needs to be further improvement in this work. Nevertheless, this method provided a weak base catalyzed one pot solvent free version of RRC/A reaction, which is a complement to the first one.

\section{Conflicts of interest}

There are no conflicts to declare.

\section{Acknowledgements}

We are grateful for the financial supports from the founds of Sichuan Province (2017JQ0023, 2017NZ0048), the founds of Chengdu City (2015-HM01-00366-SF), the Chunhui Project (Z2016162), the Undergraduate Scientific and Technological Innovation Project(20160623006), the Open Fund of the Key Laboratory of Sichuan Province (SZjj2017-031) and the Innovation Foundation of Graduate Student of Xihua University.

\section{Notes and references}

1 F. F. Fleming, Nat. Prod. Rep., 1999, 16, 597-606.

2 F. F. Fleming, L. Yao, P. C. Ravikumar, L. Funk and B. C. Shook, J. Med. Chem., 2010, 53, 7902-7917.

3 R. Lopez and C. Palomo, Angew. Chem., Int. Ed., 2015, 54, 13170-13184.

4 F. Fleming and Q. Wang, Chem. Rev., 2003, 103, 2035-2077.

5 C. Guyon, M. C. Duclos, M. Sutter, E. Metay and M. Lemaire, Org. Biomol. Chem., 2015, 13, 7067-7075.

6 C. Zheng and S.-L. You, Chem. Soc. Rev., 2012, 41, 2498-2518.

7 Y.-Q. Yang and Z. Lu, Chin. J. Chem., 2014, 32, 650-653.

8 M. Rueping, J. Dufour and F. R. Schoepke, Green Chem., 2011, 13, 1084-1105.

9 T. Wang, X.-G. Huang, J. Liu, B. Li, J.-J. Wu, K.-X. Chen, W.-L. Zhu, X.-Y. Xu and B.-B. Zeng, Synlett, 2010, 1351-1354.

10 S. Kumar and K. K. Kapoor, Synlett, 2007, 2809-2814.

11 Y. Huang, Synlett, 2007, 2304-2305.

12 S. J. Connon, Org. Biomol. Chem., 2007, 5, 3407-3417.

13 D. B. Ramachary, M. Kishor and G. B. Reddy, Org. Biomol. Chem., 2006, 4, 1641-1646.

14 D. B. Ramachary, M. Kishor and K. Ramakumar, Tetrahedron Lett., 2006, 47, 651-656.

15 D. B. Ramachary, R. Mondal and C. Venkaiah, Org. Biomol. Chem., 2010, 8, 321-325.

16 D. B. Ramachary and G. B. Reddy, J. Org. Chem., 2010, 75, 7485. 
17 D. B. Ramachary and M. S. Prasad, Tetrahedron Lett., 2010, 51, 5246-5251.

18 D. B. Ramachary and S. Jain, Org. Biomol. Chem., 2011, 9, 1277-1300.

19 D. B. Ramachary and M. Kishor, J. Org. Chem., 2007, 72, 5056-5068.

20 D. B. Ramachary, M. Kishor and Y. V. Reddy, Eur. J. Org. Chem., 2008, 975-993.

21 D. B. Ramachary and M. Kishor, Org. Biomol. Chem., 2008, 6, 4176-4187.

22 D. B. Ramachary, C. Venkaiah, Y. V. Reddy and M. Kishor, Org. Biomol. Chem., 2009, 7, 2053-2062.

23 D. B. Ramachary and M. Kishor, Org. Biomol. Chem., 2010, 8, 2859-2867.
24 R. Madhavachary and D. B. Ramachary, Eur. J. Org. Chem., 2014, 7317-7323.

25 Q. He, Z. Xu, D. Jiang, W. Ai, R. Shi, S. Qian and Z. Wang, RSC $A d v .$, 2014, 4, 8671-8674.

26 T. He, R. Shi, Y. Gong, G. Jiang, M. Liu, S. Qian and Z. Wang, Synlett, 2016, 27, 1864-1869.

27 L. Yang, X. Ma, C. Yuan, Y. He, L. Li, S. Fang, W. Xia, T. He, S. Qian, Z. Xu, G. Li and Z. Wang, Eur. J. Med. Chem., 2017, 134, 230-241.

28 G. Weng, X. Ma, D. Fang, P. Tan, L. Wang, L. Yang, Y. Zhang, S. Qian and Z. Wang, RSC Adv., 2017, 7, 22909-22912.

29 S. Qian, T. He, W. Wang, Y. He, M. Zhang, L. Yang, G. Li and Z. Wang, Bioorg. Med. Chem., 2016, 24, 6194-6205. 